\title{
Transgender Medicare Beneficiaries and Chronic Conditions: Exploring Fee-for-Service Claims Data
}

\author{
Christina N. Dragon, MSPH, ${ }^{1}$ Paul Guerino, ScM, Erin Ewald, ScM, and Alison M. Laffan, PhD²
}

\begin{abstract}
Purpose: Data on the health and well-being of the transgender population are limited. However, using claims data we can identify transgender Medicare beneficiaries (TMBs) with high confidence. We seek to describe the TMB population and provide comparisons of chronic disease burden between TMBs and cisgender Medicare beneficiaries (CMBs), thus laying a foundation for national level TMB health disparity research.

Methods: Using a previously validated claims algorithm based on ICD-9-CM codes relating to transsexualism and gender identity disorder, we identified a cohort of TMBs using Medicare Fee-for-Service (FFS) claims data. We then describe the demographic characteristics and chronic disease burden of TMBs $(N=7454)$ and CMBs $(N=39,136,229)$.

Results: Compared to CMBs, a greater observed proportion of TMBs are young (under age 65) and Black, although these differences vary by entitlement. Regardless of entitlement, TMBs have more chronic conditions than CMBs, and more TMBs have been diagnosed with asthma, autism spectrum disorder, chronic obstructive pulmonary disease, depression, hepatitis, HIV, schizophrenia, and substance use disorders. TMBs also have higher observed rates of potentially disabling mental health and neurological/chronic pain conditions, as well as obesity and other liver conditions (nonhepatitis), compared to CMBs.

Conclusion: This is the first systematic look at chronic disease burden in the transgender population using Medicare FFS claims data. We found that TMBs experience multiple chronic conditions at higher rates than CMBs, regardless of Medicare entitlement. TMBs under age 65 show an already heavy chronic disease burden which will only be exacerbated with age.
\end{abstract}

Keywords: administrative data, aging, Medicare, transgender

\section{Introduction}

I N 2011, THE Institute of Medicine identified transgender adults as an understudied population in critical need of more health research. ${ }^{1}$ Despite the lack of nationally representative data on the transgender population, there have been substantial contributions from sources such as the National Transgender Discrimination Survey, which provide a crucial, although narrow, window into many aspects of health and well-being for transgender Americans. ${ }^{2}$ Evolving terminology has contributed to challenges in identifying transgender people. While some transgender people identify as transgender (e.g., trans woman, Male-to-Female, trans man, Female-to-Male), there are other individuals who choose only to identify themselves as male or female, in alignment with their gender identity and not their sex assigned at birth. ${ }^{3}$ Still other people do not identify within the gender binary and may use terms such as gender nonconforming, nonbinary, or gender queer. ${ }^{4,5}$ Keeping the challenges of data collection in mind, there are passive methods for identifying likely transgender individuals through administrative data that do not require the person to self-identify. ${ }^{6-8}$

There are known health disparities for transgender adults, including increased cigarette smoking, elevated risk of depression, and attempted suicide. ${ }^{9-14}$ Yet, little is known about chronic conditions in transgender adults, and data on older transgender adults are even more scarce. ${ }^{3,13,14}$ According to a 2016 analysis of data from the Behavioral Risk Factor Surveillance System, there are $\sim 1.4$ million transgender identified people in the

\footnotetext{
${ }^{1}$ Office of Minority Health, Centers for Medicare \& Medicaid Services, Baltimore, Maryland.

${ }^{2}$ Health Care Department, NORC at the University of Chicago, Bethesda, Maryland.

(c) Christina N. Dragon et al. 2017; Published by Mary Ann Liebert, Inc. This is an Open Access article distributed under the terms of the Creative Commons Attribution License, which permits unrestricted use, distribution, and reproduction in any medium, provided the original work is properly cited.
} 
United States. ${ }^{15}$ Flores et al. also found that over 217,000 transgender people were ages 65 and older, ${ }^{15}$ while others estimate this population to be as high as $700,000 .{ }^{16}$ Until transgender people feel comfortable, safe, and supported in accessing healthcare, it is likely to remain challenging to estimate the size of the transgender population, let alone collect data adequately, especially among older adults who fear discrimination. ${ }^{16}$

Transgender people often have challenges with health insurance that prevent them from receiving preventive and/or medical care. ${ }^{14,17,18}$ Medicare beneficiaries, the majority of whom qualify for Medicare through aging into the program at age 65 or having an eligible disabling condition, have the advantage of insurance coverage, although other obstacles to accessing care may remain. ${ }^{19}$ Our research previously identified Medicare Fee-for-Service (FFS) beneficiaries receiving transition-related care, including both those who qualified for Medicare through the age pathway (ages 65 and older), as well as through the disability pathway (ages 18-64). ${ }^{6}$

This article illuminates the chronic disease burden in the FFS transgender Medicare beneficiary (TMB) population and differences in chronic diseases in those entitled on age versus those entitled on disability. By presenting comparisons of these populations who are under 65 or 65 and older, we observe how chronic conditions can intensify or increase with age. In addition, many of the beneficiaries who qualify for Medicare through disability will eventually age into the 65 and older group and we can view that as a forecast of how the Medicare population may change in the future. Research is still emerging for the older and disabled transgender populations, and this analysis of Medicare claims data contributes to this critical area.

\section{Methods}

\section{Data source and study population}

Using Medicare claim records accessed through the Centers for Medicare \& Medicaid Services (CMS) Chronic Conditions Data Warehouse (CCW), we identified all FFS beneficiaries eligible and alive at the start of 2015 and not entitled based on end-stage renal disease alone $(N=39,143,683)$. Beneficiaries were then separated into four groups based on gender identity and entitlement: disabled TMBs $(N=5321)$, disabled cisgender Medicare beneficiaries (CMBs; $N=6,548,168$ ), aged TMBs $(N=2133)$, and aged CMBs $(N=32,588,061)$. The Institutional Review Board at NORC at the University of Chicago approved this study.

The data used in this study have no sampling error because we used the entire universe of claims filed in Medicare in 2015 as our data source and examined the full Medicare population for this study. Thus, statistical testing, which is used to quantify the possible variation and uncertainty around the inferences drawn from a sample, is not needed. There is no statistical uncertainty, and all observed differences are true differences within the Medicare FFS population.

\section{Identifying transgender beneficiaries}

From the Medicare FFS administrative claims data, we identified TMBs using the International Classification of Diseases, Ninth Revision, Clinical Modification (ICD-9-CM) diagnosis codes for sexual and gender identity disorders $\left(302.50,302.51,302.52,302.53,302.6\right.$, and 302.85). ${ }^{20}$ All
Medicare Part A and B claims from January 1, 2010 through September 30, 2015 were searched for these ICD-9-CM codes in any position on the claim (after September 30, 2015, Medicare began using ICD-10 codes). Claim types included inpatient and outpatient hospital, carrier (e.g., physician and physician extenders), skilled nursing facility, home health agency, and durable medical equipment. After identifying all claims with at least one of these codes, we used beneficiary identification numbers to identify unique individuals and linked those individuals to 2015 CMS FFS claims data containing Medicare enrollment information, vital status, demographics, and indicators for chronic conditions and potentially disabling conditions. Our method is designed to minimize misclassification of beneficiaries as transgender and has been used with Medicare claims elsewhere. ${ }^{\circ}$ However, an unknown number of TMBs, including those who do not seek medical care, may be misclassified as CMBs.

\section{Measures}

Beneficiary age and race/ethnicity were reported based on information available in 2015 Medicare enrollment data. Age is reported as beneficiary age at the end of 2015. In Medicare records, race and ethnicity are combined into a single parameter with seven mutually exclusive categories: White, Black, Hispanic, American Indian/Alaska Native, Asian/Pacific Islander, Other, and Unknown. ${ }^{21}$

Twenty chronic conditions were chosen based on standard definitions and measures identified for use in administrative health data. ${ }^{22,23}$ Standard groupings to define multiple chronic conditions (MCCs) were applied to present the chronic condition burden $\left(0-1,2-3,4-5\right.$, and $6+$ chronic conditions)..$^{22,24,25}$

In addition to the 20 chronic conditions, 12 potentially disabling conditions were identified based on prior knowledge and availability in Medicare claims data. The potentially disabling conditions were identified using indicators based on validated algorithms available in the CCW. ${ }^{23}$

\section{Analytic methods}

Cross-tabulations of categorical variables for age, race/ethnicity, chronic condition burden, and individual chronic and potentially disabling conditions were performed on 2015 Medicare data. Comparisons are made between TMBs and CMBs overall, among those who qualified for Medicare based on disability, and among those who qualified for Medicare based on age. All analyses were performed in the CMS Virtual Research Data Center environment using SAS version 9.4 (SAS Institute Inc., Cary, NC). Analysis was performed on $100 \%$ Medicare claims data, which means that there is no sampling error in our observed estimates and no need to perform statistical testing.

\section{Results}

\section{Demographics}

Overall, TMBs are younger than CMBs (Table 1). This is driven in large part by the fact that $71.4 \%$ of TMBs are entitled on disability, who are by definition under age 65 , compared to $16.7 \%$ of CMBs. Within the group of beneficiaries entitled on disability, TMBs are younger than CMBs, with almost double the percentage of beneficiaries for ages $18-44$ (46.6\% vs. $23.7 \%$, respectively). Similarly, among 
Table 1. Age and Race/Ethnicity of Medicare Beneficiaries, by Gender Identity and Medicare Entitlement, 2015

\begin{tabular}{|c|c|c|c|c|c|c|}
\hline \multirow[b]{2}{*}{ Characteristic } & \multirow{2}{*}{$\begin{array}{c}\text { All transgender } \\
\text { beneficiaries }\end{array}$} & \multirow{2}{*}{$\begin{array}{c}\text { All cisgender } \\
\text { beneficiaries }\end{array}$} & \multicolumn{2}{|c|}{ Entitled on disability $^{\mathrm{a}}$} & \multicolumn{2}{|c|}{ Entitled on age $e^{\mathrm{a}}$} \\
\hline & & & Transgender & Cisgender & Transgender & Cisgender \\
\hline$N$ & 7454 & $39,136,229$ & 5321 & $6,548,168$ & 2133 & $32,588,061$ \\
\hline Subpopulation $\%$ & & & $71.4 \%$ & $16.7 \%$ & $28.6 \%$ & $83.3 \%$ \\
\hline Mean age (SD) & $53.1(16.6)$ & $70.9(12.4)$ & $44.9(11.5)$ & $51.3(10.5)$ & $73.4(7.6)$ & $74.8(8.4)$ \\
\hline \multicolumn{7}{|l|}{ Age } \\
\hline $18-44$ years & 33.2 & 4.0 & 46.6 & 23.7 & N/A & N/A \\
\hline $45-54$ years & 20.2 & 4.7 & 28.4 & 27.8 & N/A & N/A \\
\hline 55-64 years & 17.9 & 8.1 & 25.1 & 48.5 & N/A & N/A \\
\hline $65-74$ years & 19.2 & 47.7 & $\mathrm{~N} / \mathrm{A}^{\mathrm{a}}$ & $\mathrm{N} / \mathrm{A}$ & 67.1 & 57.2 \\
\hline $75-84$ years & 6.4 & 23.3 & N/A & $\mathrm{N} / \mathrm{A}$ & 22.2 & 28.0 \\
\hline 85 years and older & 3.1 & 12.3 & N/A & N/A & 10.7 & 14.7 \\
\hline \multicolumn{7}{|l|}{ Race/ethnicity ${ }^{\mathrm{b}}$} \\
\hline White & 76.8 & 78.1 & 72.7 & 67.6 & 86.8 & 80.2 \\
\hline Black & 12.3 & 9.6 & 15.5 & 18.9 & 4.5 & 7.8 \\
\hline American Indian/Alaska Native & 1.0 & 0.6 & 1.1 & 1.0 & 0.6 & 0.5 \\
\hline Asian/Pacific Islander & 1.7 & 2.8 & 1.5 & 1.6 & 2.0 & 3.0 \\
\hline Hispanic & 6.4 & 6.7 & 7.4 & 9.3 & 3.8 & 6.2 \\
\hline Other & 0.7 & 0.8 & 0.7 & 0.7 & 0.7 & 0.9 \\
\hline Unknown & 1.2 & 1.4 & 1.0 & 0.9 & 1.6 & 1.5 \\
\hline
\end{tabular}

Medicare Master Beneficiary Summary File (MBSF), 2015; data available in the CMS Chronic Conditions Data Warehouse (CCW) Virtual Research Data Center (VRDC). Excludes beneficiaries with end-stage renal disease. Percentages may not add up to $100.0 \%$ due to rounding.

${ }^{a}$ Because entitlement reason is defined based, in part, on age of Medicare beneficiaries, no beneficiary categorized as "Entitled on Disability" will be 65 years or older; likewise, no beneficiary categorized as "Entitled on Age" will be under 65 years.

'Categories are mutually exclusive (e.g., "White" indicates non-Hispanic White, "Black" indicates non-Hispanic Black).

beneficiaries entitled on age, a higher percentage of TMBs are between the ages of 65 and $74(67.1 \%$ vs. $57.2 \%$ for CMBs), and a lower percentage of TMBs are age 85 and older ( $10.7 \%$ vs. $14.7 \%$ for CMBs).

The majority of TMBs and CMBs overall and in each entitlement category are White (Table 1 ). When comparing all TMBs with all CMBs, a greater percentage of TMBs are Black $(12.3 \%$ vs. $9.6 \%$ for CMBs). However, due to the fact that the majority of TMBs are entitled on disability (71.4\%), but the majority of CMBs are entitled on age $(83.3 \%)$, this relationship is reversed (i.e., a greater percentage of CMBs are Black) when observing the corresponding percentages within each entitlement category. This reversal of relationship is due to the extreme difference in distribution of TMBs and CMBs across the two entitlement groups (i.e., Simpson's paradox).

\section{Chronic condition burden}

TMBs have a higher observed burden of chronic conditions than CMBs, both overall and within each entitlement category (Figure 1). Overall, 88.2\% of TMBs have MCCs (defined as more than one chronic condition), whereas $72.4 \%$ of CMBs have MCCs. In addition, a much higher percentage of TMBs have six or more chronic conditions; this relationship holds across the overall population (39.7\% vs. $32.3 \%$ for CMBs), beneficiaries entitled on disability (36.2\% vs. $25.6 \%$ for CMBs), and beneficiaries entitled on age (48.6\% vs. $33.6 \%)$.

\section{Chronic conditions}

Considering each chronic condition separately in the overall population (Table 2), TMBs have higher observed percent- ages of asthma (29.6\% vs. $13.6 \%$ in CMBs), autism spectrum disorder (3.0\% vs. $0.3 \%$ in CMBs), chronic obstructive pulmonary disease (COPD) (27.3\% vs. $20.8 \%$ in CMBs), depression $(76.3 \%$ vs. $28.8 \%$ in CMBs), hepatitis ( $8.6 \%$ vs. $1.7 \%$ in CMBs), HIV (11.2\% vs. $0.4 \%$ in CMBs), schizophrenia (22.1\% vs. $2.3 \%$ in $\mathrm{CMBs}$ ), and substance use disorders (26.6\% vs. $4.2 \%$ in CMBs). These relationships also persist when observing the percentages within both entitlement categories. Conversely, a lower percentage of TMBs are observed to have cancer, cardiac arrhythmia, and osteoporosis, compared to CMBs; these conditions are much more common in beneficiaries of ages 65 and older by a factor of three or more and thus appear less often overall for TMBs than CMBs.

When observing only beneficiaries entitled on age (Table 2 ), a higher percentage of TMBs have arthritis (54.7\% vs. $45.6 \%$ in CMBs), chronic kidney disease (33.5\% vs. $23.1 \%$ in CMBs), congestive heart failure ( $27.5 \%$ vs. $20.9 \%$ in CMBs), coronary artery disease ( $47.8 \%$ vs. $38.3 \%$ in CMBs), dementia $(18.2 \%$ vs. $12.2 \%$ in CMBs), diabetes (38.6\% vs. $30.6 \%$ in CMBs), hyperlipidemia $(75.9 \%$ vs. $64.8 \%$ in CMBs), hypertension (77.5\% vs. $66.9 \%$ in CMBs), and stroke (16.5\% vs. $12.2 \%$ in CMBs). ${ }^{26-33}$

\section{Potentially disabling conditions}

Overall, TMBs had much higher observed percentages of all mental health and neurological/chronic pain conditions, as well as obesity and other nonhepatitis liver conditions, compared to CMBs (Table 3). This relationship also persists in both entitlement groups. In addition, among beneficiaries entitled on age, a higher percentage of TMBs had peripheral vascular disease (26.2\% vs. $17.9 \%$ in $\mathrm{CMBs}$ ). 


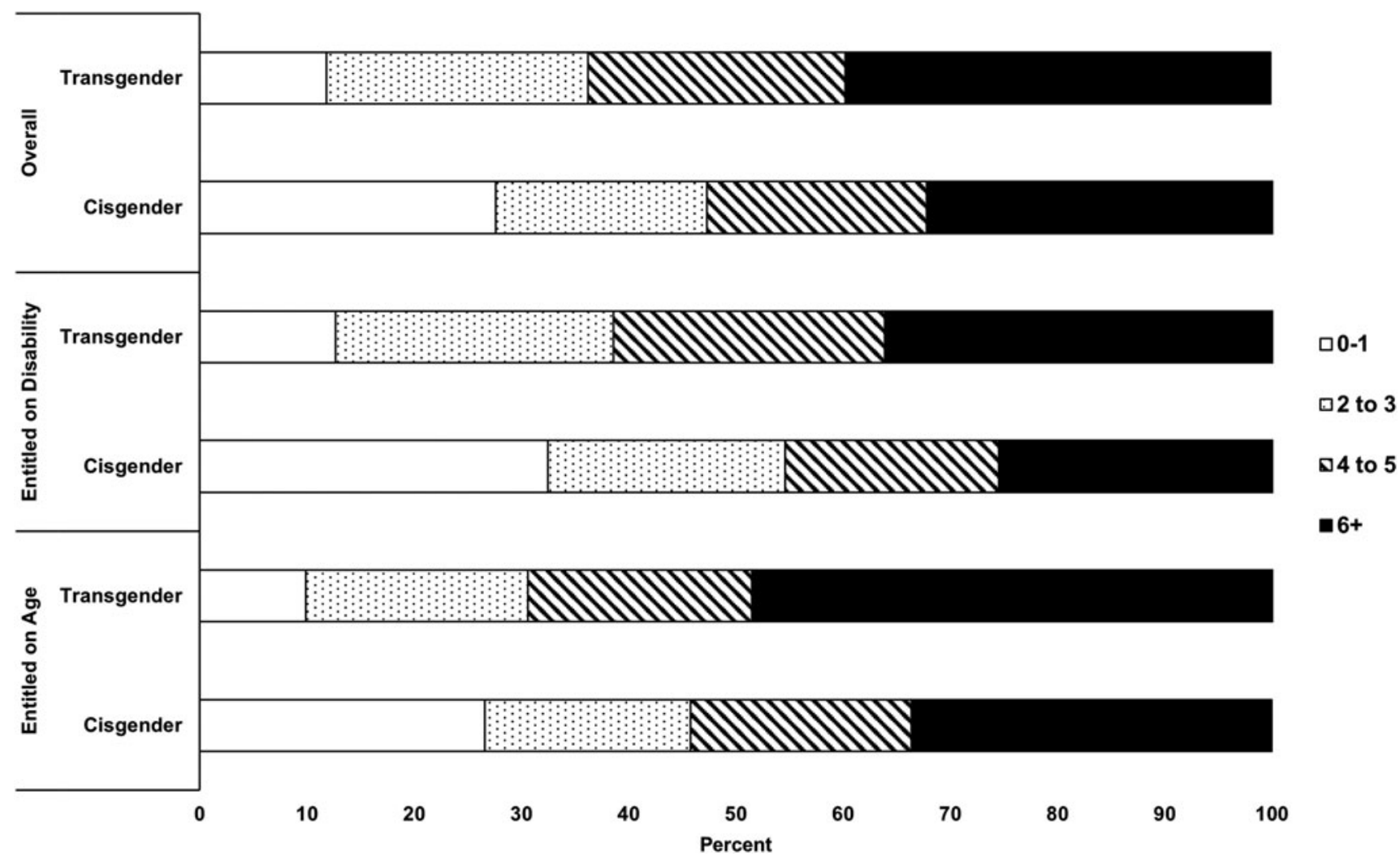

FIG. 1. Number of chronic conditions, by gender identity and Medicare entitlement, 2015.

Table 2. Percentage of Medicare Beneficiaries with Chronic Conditions, by Gender Identity AND Medicare Entitlement, 2015

\begin{tabular}{|c|c|c|c|c|c|c|}
\hline \multirow[b]{2}{*}{ Characteristic } & \multirow{2}{*}{$\begin{array}{c}\text { All transgender } \\
\text { beneficiaries }\end{array}$} & \multirow{2}{*}{$\begin{array}{l}\text { All cisgender } \\
\text { beneficiaries }\end{array}$} & \multicolumn{2}{|c|}{ Entitled on disability $^{\mathrm{a}}$} & \multicolumn{2}{|c|}{ Entitled on age $e^{\mathrm{a}}$} \\
\hline & & & Transgender & Cisgender & Transgender & Cisgender \\
\hline Arthritis & 39.2 & 43.6 & 32.9 & 33.4 & 54.7 & 45.6 \\
\hline Asthma & 29.6 & 13.6 & 33.2 & 18.0 & 20.9 & 12.7 \\
\hline Autism spectrum disorder & 3.0 & 0.3 & 4.0 & 1.3 & 0.4 & 0.0 \\
\hline Cancer & 5.7 & 11.4 & 2.9 & 3.8 & 12.9 & 13.0 \\
\hline Cardiac arrhythmia & 6.3 & 11.4 & 2.6 & 3.4 & 15.7 & 13.0 \\
\hline Chronic kidney disease & 23.1 & 22.1 & 18.9 & 17.5 & 33.5 & 23.1 \\
\hline Congestive heart failure & 16.0 & 19.7 & 11.4 & 13.5 & 27.5 & 20.9 \\
\hline COPD & 27.3 & 20.8 & 26.1 & 21.0 & 30.4 & 20.7 \\
\hline Coronary artery disease & 30.4 & 35.7 & 23.4 & 23.1 & 47.8 & 38.3 \\
\hline Dementia & 10.2 & 11.0 & 6.9 & 4.8 & 18.2 & 12.2 \\
\hline Depression & 76.3 & 28.8 & 85.5 & 47.9 & 53.5 & 24.9 \\
\hline Diabetes & 31.1 & 30.2 & 28.2 & 28.0 & 38.6 & 30.6 \\
\hline Hepatitis & 8.6 & 1.7 & 10.1 & 5.1 & 5.0 & 1.0 \\
\hline HIV & 11.2 & 0.4 & 14.6 & 1.7 & 2.5 & 0.1 \\
\hline Hyperlipidemia & 61.1 & 61.6 & 55.2 & 45.5 & 75.9 & 64.8 \\
\hline Hypertension & 59.9 & 64.2 & 52.8 & 51.0 & 77.5 & 66.9 \\
\hline Osteoporosis & 8.2 & 15.7 & 4.5 & 5.5 & 17.5 & 17.7 \\
\hline Schizophrenia & 22.1 & 2.3 & 28.2 & 9.6 & 6.7 & 0.9 \\
\hline Stroke & 9.0 & 11.2 & 5.9 & 6.7 & 16.5 & 12.2 \\
\hline Substance use & 26.6 & 4.2 & 33.8 & 14.8 & 8.44 & 2.0 \\
\hline
\end{tabular}

Medicare chronic conditions files, 2015; data available in the CMS Chronic Conditions Data Warehouse (CCW) Virtual Research Data Center (VRDC). Excludes beneficiaries with end-stage renal disease.

${ }^{a}$ Because entitlement reason is defined based, in part, on age of Medicare beneficiaries, no beneficiary categorized as "Entitled on Disability" will be 65 years or older; likewise, no beneficiary categorized as "Entitled on Age" will be under 65 years.

COPD, chronic obstructive pulmonary disease; HIV, human immunodeficiency virus 
Table 3. Percentage of Medicare Beneficiaries with Potentially Disabling Conditions, By Gender Identity and Medicare Entitlement, 2015

\begin{tabular}{|c|c|c|c|c|c|c|}
\hline \multirow[b]{2}{*}{ Characteristic } & \multirow{2}{*}{$\begin{array}{l}\text { All transgender } \\
\text { beneficiaries }\end{array}$} & \multirow{2}{*}{$\begin{array}{l}\text { All cisgender } \\
\text { beneficiaries }\end{array}$} & \multicolumn{2}{|c|}{ Entitled on disability $^{\mathrm{a}}$} & \multicolumn{2}{|c|}{ Entitled on age $e^{\mathrm{a}}$} \\
\hline & & & Transgender & Cisgender & Transgender & Cisgender \\
\hline \multicolumn{7}{|l|}{ Mental health } \\
\hline Anxiety disorders & 62.4 & 20.2 & 71.8 & 34.2 & 38.9 & 17.3 \\
\hline Bipolar disorder & 39.9 & 4.9 & 51.0 & 17.4 & 12.4 & 2.4 \\
\hline Depression & 67.4 & 22.3 & 76.1 & 38.5 & 45.6 & 19.1 \\
\hline Personality disorders & 25.3 & 1.6 & 32.2 & 6.1 & 8.1 & 0.7 \\
\hline Post-traumatic stress disorder & 22.7 & 1.6 & 29.2 & 6.3 & 6.2 & 0.6 \\
\hline $\begin{array}{l}\text { Schizophrenia and other } \\
\text { psychotic disorders }\end{array}$ & 26.7 & 5.6 & 36.3 & 13.0 & 13.3 & 4.1 \\
\hline \multicolumn{7}{|l|}{ Neurological/chronic pain } \\
\hline Epilepsy & 10.5 & 3.3 & 12.7 & 8.6 & 5.1 & 2.2 \\
\hline Fibromyalgia & 37.2 & 20.7 & 39.5 & 30.3 & 31.7 & 18.7 \\
\hline Migraine & 14.8 & 4.4 & 18.2 & 10.1 & 6.3 & 3.2 \\
\hline \multicolumn{7}{|l|}{ Other } \\
\hline Obesity & 31.3 & 17.2 & 34.8 & 25.4 & 22.6 & 15.6 \\
\hline Nonhepatitis liver conditions & 12.0 & 7.3 & 12.0 & 9.6 & 12.1 & 6.8 \\
\hline Peripheral vascular disease & 13.2 & 16.5 & 8.0 & 9.6 & 26.2 & 17.9 \\
\hline
\end{tabular}

Medicare chronic conditions files, 2015; data available in the CMS Chronic Conditions Data Warehouse (CCW) Virtual Research Data Center (VRDC). Excludes beneficiaries with end-stage renal disease.

${ }^{a}$ Because entitlement reason is defined based, in part, on age of Medicare beneficiaries, no beneficiary categorized as "Entitled on Disability" will be 65 years or older; likewise, no beneficiary categorized as "Entitled on Age" will be under 65 years.

\section{Discussion}

Consistent with the larger literature that has found that people who identify as transgender are more likely to be younger, our research also found that the transgender Medicare population skewed younger compared to their cisgender peers. ${ }^{34} \mathrm{We}$ also found that higher percentages of TMBs experience chronic conditions regardless of entitlement status, including asthma, autism spectrum disorder, COPD, depression, hepatitis, HIV, schizophrenia, and substance use. This is consistent with the limited evidence available in the literature that transgender adults are diagnosed with more chronic conditions. ${ }^{1,10,35}$ Potentially disabling conditions were also much more common in TMBs than CMBs, including a range of mental health, neurological, and chronic pain conditions. Our findings on the potentially disabling mental health conditions were especially notable, indicating that those conditions were much more common in TMBs than in CMBs by upwards of 20 percentage points for most conditions. These findings, while striking, align with what has been reported in much of the previous literature on transgender patients. ${ }^{2,36-39}$

In addition, we observed disparities among older TMBs, who were entitled to Medicare based on age. Although rates of chronic conditions in this group were high for both TMBs and CMBs, many chronic conditions that typically occur or worsen in older ages were observed to be even more common among TMBs. ${ }^{26-33}$ In this study, we observed that TMBs had higher rates of hypertension, congestive heart failure, coronary artery disease, hyperlipidemia, arthritis, dementia, stroke, Chronic Kidney Disease, and diabetes, compared to their CMB counterparts. The literature on the burden of these types of nonmental health chronic conditions in transgender individuals is very sparse, especially in the United States, and even more so for older transgender adults. ${ }^{40}$ Two small studies have shown similar findings for cardiovascular disease and diabetes; however, the studies were both conducted only with transgender patients on hormone therapy, and effects varied by sex assigned at birth. ${ }^{41,42} \mathrm{~A}$ narrative review provides additional examination of transgender people taking hormones and the risk factors for cardiovascular disease. ${ }^{43}$ More research is needed into the intersectional effects of aging and chronic conditions in older transgender patients.

Looking at the racial/ethnic characteristics of TMBs also illuminates further possibilities for research into health disparities. Substantial evidence suggests that racial/ethnic minorities experience worse health outcomes and more chronic conditions than their White peers. This phenomenon will likely only be exacerbated because of the compounding forces of being both transgender and a racial/ethnic minority. ${ }^{11,44}$

\section{Limitations}

Because our research was limited to using ICD-9-CM diagnosis codes from claims data, we may have misclassified some TMBs as CMBs if their identity or transition status was not reflected in the codes. Other approaches using additional information not available in claims data have yielded a more complete picture of the transgender population. For instance, Roblin et al. conducted similar analyses using electronic health records and supplemented diagnostic codes with key word searches. ${ }^{8}$ Similarly, research using electronic health records at the Veterans Health Administration cross-checked ICD-9 codes with patient histories and other health record documentation. ${ }^{7}$ However, administrative records still provide a rich source of information on transgender health and wellbeing that can pave the way for increased data collection in national surveys and more uniform clinical data reporting.

Some of the differences in chronic conditions we observed may be due, at least in part, to the fact that TMBs are more 
likely to be disabled than the CMB community and future research should consider accounting for this through matched pair analysis.

Our findings do not report on sex or gender identity; Medicare records do not include separate sex and gender variables, and it is therefore not possible to separate sex assigned at birth from gender identity. While some TMBs may have officially changed their sex to reflect their gender identity, these changes may or may not be reflected in the data available in Medicare claims.

Systemic issues of discrimination and pervasive distrust of healthcare providers may lead transgender people to delay or defer even basic healthcare for prevention and treatment of chronic conditions. ${ }^{4,7}$ Some transgender people may also delay transition-related care that is essential to their health and well-being, which would preclude them from being visible in claim records. As a result, our study may underestimate the number of TMBs - they may simply avoid care or the care that they receive may not be captured by the ICD9-CM codes used in our research.

\section{Future research}

As the literature on the transgender population continues to grow, more research is needed to better understand the unique needs of the transgender Medicare population. Improving data collection and analysis methods from claims and other sources (e.g., electronic health record data, surveys, etc.) can significantly enhance data availability for analysis of the transgender population. ${ }^{8,45}$ This is particularly important given that at time of authorship no current national survey or administrative health data collection strategy explicitly mandates the collection of gender identity. The final rule for Certified Electronic Health Record Technology requires that electronic health records have the ability to collect gender identity in the demographic section. ${ }^{46}$ However, this is no guarantee that providers will ensure that gender identity data are collected.

Other efforts are also underway to address the issue of accurate identification of transgender individuals. In 2016, a Federal Interagency Working Group was convened to review identification and measurement of sexual and gender minority populations in federal surveys, with the aim of improving data quality and setting a federal research agenda. ${ }^{45,47,48}$ Priority areas recommended for future research include refining question terminology (e.g., cultural and linguistic groups may not identify with the term "transgender"), examining the effects of proxy reporting, and translation of sexual orientation and gender identity questions into other languages. ${ }^{48}$ These recommendations are a necessary first step for accurate identification of transgender individuals in the broader population and will provide a more standardized structure for reporting population estimates for all sexual and gender minorities. As more data become available through national surveys, electronic health records, and other administrative data systems, we will be better equipped to discover additional trends in chronic disease burden, healthcare access, and utilization.

\section{Conclusion}

This study provides a clearer picture of the comorbidity profile of TMBs; future research should build upon this foun- dation and work toward ways to reduce disparities. Eliminating health disparities and achieving health equity is a core goal for Healthy People 2020, and by identifying these disparities for TMBs, we can begin to address them. ${ }^{49}$ While many of our findings echoed results seen in previous studies, especially in regards to race/ethnicity and prevalence of mental health conditions, we also observed lesser-noted findings such as higher prevalence of many age-associated chronic conditions among older TMBs; these results warrant further investigation. In addition, more research is needed into the intersection of gender identity, race/ethnicity, and Medicare entitlement and how that affects chronic condition burden. Our findings continue to build an evidence base not only for researchers but also for clinicians to draw from as they care for transgender patients.

\section{Acknowledgment}

This work was supported, in part, by the Centers for Medicare \& Medicaid Services under Contract Number HHSM500-2011-00002I Task order HHSM-500-T0012 with NORC at the University of Chicago.

\section{Disclaimers}

The views expressed in this article are those of the authors and do not necessarily represent the views of the Centers for Medicare \& Medicaid Services or the U.S. Department of Health and Human Services.

\section{Author Disclosure Statement}

No competing financial interests exist.

\section{References}

1. Institute of Medicine (US) Committee on Lesbian, Gay, Bisexual, and Transgender Health Issues and Research Gaps and Opportunities: The Health of Lesbian, Gay, Bisexual, and Transgender People: Building a Foundation for Better Understanding. Washington, DC: National Academies Press (US), 2011.

2. Grant JM, Mottet LA, Tanis J, et al.: Injustice at Every Turn: A Report of the National Transgender Discrimination Survey. Washington, DC: National Center for Transgender Equality and National Gay and Lesbian Task Force, 2011.

3. Lombardi E: Enhancing transgender health care. Am J Public Health 2001;91:869-872.

4. Edmiston EK, Donald CA, Sattler AR, et al.: Opportunities and gaps in primary care preventative health services for transgender patients: A systematic review. Transgender Health 2016;1:216-230.

5. Rood BA, Reisner SL, Surace FI, et al.: Expecting rejection: Understanding the minority stress experiences of transgender and gender-nonconforming individuals. Transgender Health 2016;1:151-164.

6. Proctor K, Haffer SC, Ewald E, et al.: Identifying the transgender population in the Medicare program. Transgender Health 2016;1:250-265.

7. Blosnich JR, Brown GR, Shipherd JC, et al.: Prevalence of gender identity disorder and suicide risk among transgender veterans utilizing veterans health administration care. Am J Public Health 2013;103:e27-e32.

8. Roblin D, Barzilay J, Tolsma D, et al.: A novel method for estimating transgender status using electronic medical records. Ann Epidemiol 2016;26:198-203. 
9. Office of Disease Prevention and Health Promotion. Healthy People 2020. 2016. Available at https://www.healthypeople .gov Accessed November 14, 2016.

10. Conron KJ, Scott G, Stowell GS, Landers SJ: Transgender health in Massachusetts: Results from a household probability sample of adults. Am J Public Health 2012;102:118-122.

11. Clements-Nolle K, Marx R, Guzman R, Katz M: HIV prevalence, risk behaviors, health care use, and mental health status of transgender persons: Implications for public health intervention. Am J Public Health 2001;91:915-921.

12. Sinnard MT, Raines CR, Budge SL: The association between geographic location and anxiety and depression in transgender individuals: An exploratory study of an online sample. Transgender Health 2016;1:181-186.

13. White Hughto JM, Murchison GR, Clark K, et al.: Geographic and individual differences in healthcare access for U.S. transgender adults: A multilevel analysis. LGBT Health 2016;3:424-433.

14. Fredriksen-Goldsen KI, Cook-Daniels L, Kim HJ, et al.: Physical and mental health of transgender older adults: An at-risk and underserved population. Gerontologist 2014;54:488-500.

15. Flores AR, Herman JL, Gates GJ, et al.: How Many Adults Identify as Transgender in the United States? Los Angeles, CA: The Williams Institute, 2016.

16. Witten TM, Eyler AE: Gay, Lesbian, Bisexual, \& Transgender Aging: Challenges in Research, Practice, \& Policy. Baltimore, MD: Johns Hopkins University Press, 2012.

17. Bradford J, Reisner SL, Honnold JA, Xavier J: Experiences of transgender-related discrimination and implications for health: Results from the Virginia Transgender Health Initiative Study. Am J Public Health 2013;103:1820-1829.

18. Dickey LM, Budge SL, Katz-Wise SL, Garza MV: Health disparities in the transgender community: Exploring differences in insurance coverage. Psychol Sex Orientat Gender Divers 2016;3:275-282.

19. United States Department of Health \& Human Services: Who is eligible for Medicare? 2014. Available at https:// www.hhs.gov/answers/medicare-and-medicaid/who-iselibible-for-medicare/index.html Accessed March 31, 2017.

20. Centers for Medicare \& Medicaid Services: ICD-9-CM Diagnosis and Procedure Codes. 2015. Available at https:// www.cms.gov/Medicare/Coding/ICD9ProviderDiagnostic Codes/codes.html Accessed November 2, 2016.

21. Eicheldinger C, Bonito A: More accurate racial and ethnic codes for Medicare administrative data. Health Care Financ Rev 2008;29:27-42.

22. Goodman RA, Posner SF, Huang ES, et al.: Defining and measuring chronic conditions: Imperatives for research, policy, program, and practice. Prev Chronic Dis 2013;10: E66.

23. Centers for Medicare \& Medicaid Services: Chronic Conditions Data Warehouse: Condition Categories. Available at https://www.ccwdata.org/web/guest/condition-categories Accessed November 2, 2016.

24. Lochner KA, Cox CS: Prevalence of multiple chronic conditions among Medicare beneficiaries, United States, 2010. Prev Chronic Dis 2013;10:E61.

25. Lochner KA, Goodman RA, Posner S, Parekh A: Multiple chronic conditions among Medicare Beneficiaries: Statelevel variations in prevalence, utilization, and cost, 2011. Medicare Medicaid Res Rev 2013;3:pii: mmrr003.03.b02.

26. Carrero JJ, Hecking M, Ulasi I: Chronic kidney disease, gender, and access to care: A global perspective. Semin Nephrol 2017;37:296-308.
27. Mahmood SS, Wang TJ: The epidemiology of congestive heart failure: Contributions from the Framingham Heart Study. Glob Heart 2013;8:77-82.

28. Burt VL, Whelton P, Roccella EJ, et al.: Prevalence of hypertension in the US adult population: Results from the Third National Health and Nutrition Examination Survey, 1988-1991. Hypertension 1995;25:305-313.

29. Lloyd-Jones D, Adams RJ, Brown TM, et al.: Heart disease and stroke statistics-2010 update: A report from the American Heart Association. Circulation 2010;121:e46e215.

30. Crawford AG, Cote C, Couto J, et al.: Prevalence of obesity, type II diabetes mellitus, hyperlipidemia, and hypertension in the United States: Findings from the GE Centricity Electronic Medical Record database. Pop Health Manag 2010; 13:151-161.

31. Sosa-Ortiz AL, Acosta-Castillo I, Prince MJ: Epidemiology of dementias and Alzheimer's disease. Arch Med Res 2012;43:600-608.

32. Prince M, Bryce R, Albanese E, et al.: The global prevalence of dementia: A systematic review and metaanalysis. Alzheimers' Dement 2013;9:63-75. e2.

33. Reginster JY: The prevalence and burden of arthritis. Rheumatology (Oxford) 2002;41 Suppl 1:3-6.

34. Herman JL, Flores AR, Brown TNT, et al.: Age of Individuals Who Identify as Transgender in the United States. Los Angeles, CA: The Williams Institute, 2017.

35. Arnold JD, Sarkodie EP, Coleman ME, Goldstein DA: Incidence of venous thromboembolism in transgender women receiving oral estradiol. J Sex Med 2016;13: 1773-1777.

36. Brown GR, Jones KT: Mental health and medical health disparities in 5135 transgender veterans receiving healthcare in the Veterans Health Administration: A case-control study. LGBT Health 2016;3:122-131.

37. Su D, Irwin JA, Fisher C, et al.: Mental health disparities within the LGBT population: A comparison between transgender and nontransgender individuals. Transgender Health 2016;1:12-20.

38. Reisner SL, White JM, Bradford JB, et al.: Transgender health disparities: Comparing full cohort and nested matched-pair study designs in a community health center. LGBT Health 2014;1:177-184.

39. Reisner SL, Vetters R, Leclerc M, et al.: Mental health of transgender youth in care at an adolescent urban community health center: A matched retrospective cohort study. J Adolesc Health 2015;56:274-279.

40. Feldman J, Brown GR, Deutsch MB, et al.: Priorities for transgender medical and healthcare research. Curr Opin Endocrinol Diabetes Obes 2016;23:180-187.

41. Wierckx K, Mueller S, Weyers S, et al.: Long-term evaluation of cross-sex hormone treatment in transsexual persons. J Sex Med 2012;9:2641-2651.

42. Wierckx K, Elaut E, Declercq E, et al.: Prevalence of cardiovascular disease and cancer during cross-sex hormone therapy in a large cohort of trans persons: A case-control study. Eur J Endocrinol 2013;169:471-478.

43. Streed C, Harfouch O, Marvel F, et al.: Cardiovascular disease among transgender adults receiving hormone therapy: A narrative review. Ann Intern Med 2017;167:256267.

44. National Center for Health Statistics: Health, United States, 2015: With Special Feature on Racial and Ethnic Health Disparities. Hyattsville, MD, 2016. 
45. Federal Interagency Working Group on Improving Measurement of Sexual Orientation and Gender Identity in Federal Surveys: Current measures of sexual orientation and gender identity in Federal Surveys. 2016. Available at https:// s3.amazonaws.com/sitesusa/wp-content/uploads/sites/242/ 2014/04/current_measures_20160812.pdf Accessed April 5, 2017.

46. Department of Health and Human Services, Office of the Secretary: 45 CFR Part 170: 2015 Edition Health Information Technology (Health IT) Certification Criteria, 2015 Edition Base Electronic Health Record (EHR) Definition, and ONC Health IT Certification Program Modifications; Final Rule. Federal Register, 2015.

47. Federal Interagency Working Group on Improving Measurement of Sexual Orientation and Gender Identity in Federal Surveys: Toward a research agenda for measuring sexual orientation and gender identity in Federal Surveys: Findings, recommendations, and next steps. 2016. Available at https://s3.amazonaws.com/sitesusa/wp-content/uploads/ sites/242/2014/04/SOGI_Research_Agenda_Final_Report_ 20161020.pdf Accessed April 5, 2017.
48. Federal Interagency Working Group on Improving Measurement of Sexual Orientation and Gender Identity in Federal Surveys: Evaluations of sexual orientation and gender identity survey measures: What have we learned? 2016. Available at https://s3.amazonaws.com/sitesusa/wp-content/uploads/ sites/242/2014/04/Evaluations_of_SOGI_Questions_20160923 .pdf Accessed April 5, 2017.

49. Office of Disease Prevention and Health Promotion: Healthy People 2020: Disparities. 2017. Available at https://www .healthypeople.gov/2020/about/foundation-health-measures/ Disparities Accessed March 31, 2017.

Address correspondence to: Christina N. Dragon, MSPH Office of Minority Health Centers for Medicare \& Medicaid Services 7500 Security Boulevard, Mailstop S2-12-17 Baltimore, MD 21244-1850

E-mail: christina.dragon@cms.hhs.gov 